\title{
The gendered elements of homosexual marriage and society's reactions to the issue
}

\author{
K. Brow \\ School of Social Sciences, Haydon-Allen Building, The Australian National University, Acton ACT 0200, \\ Canberra, Australia
}

The following analysis will be carried out to investigate the gendered elements of homosexual marriages and how society has reacted and revolved around the issue. It will deal with definitions of marriage and whether homosexuals fit into this definition. In addition it will explore the gendered stereotypes within same-sex relationships in regards to household roles, relationship attitudes and the raising of children.

The ever controversial issue of homosexual marriage has remained contentious since the term was introduced, primarily because it is seen as unnatural and does not correspond with what society defines as normal. While attitudes may be progressing, a conventional definition of marriage must be established in order to determine whether homosexual relationships can fit into this category. It is also important to briefly examine societies evolving attitudes towards homosexual relationships to show the progress of the gay liberation movement and its affects on society. Aside from the judgment of the heterosexual world, many myths about homosexual marriages have been imagined. These myths circulate around same-sex married couples mimicking heterosexual relationships, where one adopts a masculine role and the other the role of the housewife. Secondly, the myth that all homosexual men are promiscuous and all lesbians are completely committed to their partners (as little research has been accumulated about lesbians, they will only be discussed in brief). And finally, the myth that lesbians are naturally nurturers, allowing greater access to the adoption of children while men are discriminated against for being masculine. These myths will be discussed in further detail, establishing the gendered elements surrounding the issue of homosexual marriage.

In discussing homosexual marriage it is imperative to establish a definition of marriage and of homosexuality. Behavioural scientists describe homosexuality as a person's "emotional commitment, desire or fantasy" regarding an individual of the same sex (Talbot, 1985: 10). This definition includes public single and coupled homosexuals as well as those homosexuals who choose not to participate in the act of homosexuality yet still desire the same sex.
Finding a common definition of marriage however is complex, in that religion and the state interfere with notions of marriage for society. This article will endeavour to avoid any religious views, as there are too many variations of too many religions; to include religion would move away from the issue at hand. Marriage will therefore be defined by John Witte Jr., as:

"the Western legal tradition... (of) monogamous, heterosexual couples who had reached the age of consent, who had the physical capacity to join together in one flesh, and whose joining served the goods and goals of procreation, companionship and stability at once" (Witte, 2003: 43).

While this concept of marriage is obviously romanticised, it does however describe the partners of marriage specifically as a man and a woman who come together to procreate. This definition excludes same-sex marriages entirely. Noticeably they are excluded because they do not contain two members of the opposite sex and secondly because they cannot naturally produce children with only each other. From this exclusion, negative connotations of same-sex couples have emerged, and these relationships therefore have been deemed as deviant, anti-social and unnatural behaviour. The main reason for this is that society is more interested in favouring prospective procreative couplings compared to relationships founded on "mutually agreeable genital stimulation," (Wilkins, 2003: 232). Wilkins' opinion can be heard loudly throughout society which inherently judges homosexual relationships as unproductive, sexually selfish and aberrant. Interestingly however, childless marriages involving heterosexual couples are becoming more and more common (ABS 4102.0: 2002). Thus, perhaps it is necessary for the definition of marriage 
to adapt, excluding procreation from its definition, so as to encompass both heterosexual and homosexual childless marriages. This will be discussed in more detail in relation to homosexual couples' access to adoption. Without the modification of these heterosexually made definitions, homosexual activists have and will struggle to redefine themselves as equal members of society in order to produce a positive identity for same-sex couples

The emergence of a homosexual institution was imperative in order to encourage tolerance of homosexuals by an overwhelmingly heterosexually dominant society. Prior to the 1960s homosexuals were often victimised and ridiculed for their lifestyle choices (Stewart, 2001: 7). Most gay men and women avoided voicing their sexual preferences and often entered into heterosexual marriages, as advised by their psychologists, in order to suppress their homosexual thoughts. Thus society's opinions of homosexual marriages at this point in time were decisively negative and homosexuals were plagued by discrimination. After the demonstrations of the gay liberation movement in Greenwich, USA, in the late 1960s, homosexual rights and acceptance began to improve. Frank Kameny's aggressive pro-gay slogan of "Gay is Good" forced a situation whereby homosexual discrimination became seen as out dated, ignorant and homophobic (Phy-Olsen, 2006: 69). Other examples of gay rights campaigns surprisingly came in the form of festivals. The gay pride festival is now a celebrated calendar date for homosexuals and heterosexuals alike. Allowing the heterosexual world an insight into what was seen as an unnatural way of life produced a more accepting atmosphere for homosexuals in western society.

The gay liberation movement provided access to the establishment of a gay sub-culture. This would be the first sub-culture based on sexual preference. By the 1990s this sub-culture was so well identified that capitalism played its part and began producing homosexual exclusive products. Within this strategy of capitalism, stereotypes were introduced once more. Advertisements portrayed the gay man as living the highlife, one of luxury, style, holidays and most importantly, one free of the burden of children and marriage (Ibid: 71). Capitalism and its acceptance of homosexuals also came at a cost, bringing with it the lifestyle typecast of homosexuals.

The establishment of homosexual stereotypes encouraged the development of society's attitude towards homosexuals and whether they should marry. Using the stereotypes, which society perceived to be the normal behavioural patterns of homosexuals, an excessively negative attitude emerged regarding homosexual marriage. The main excuse heterosexuals gave when claiming that homosexuals should not marry is that they do not adequately fit in to the definition of marriage. In addition, homosexuals themselves argue that marriage is a heterosexual institution and the idea of submitting to it, is in contradiction of what the gay liberation movement sort to accomplish (Ibid: 113). Marriage to homosexuals was viewed as a patriarchal and oppressive structure put in place to monitor and regulate a heterosexual society. Thus, the idea of homosexuals wishing to conform to the heterosexual institution that is marriage is inexplicable. Public opinion surrounding this debate is vast and extensive, while the majority of opinions stemming from heterosexuals tend to be against same-sex marriage, some do consider that every human has the right to marry whom ever they choose. It is unfortunate that homosexuals have acquired such reputations as they constantly burden their lifestyle choices and actions. Gender-role socialisation is a leading contributor to the establishment and the continuation of these stigmatic homosexual stereotypes.

\section{STEREOTYPES WITHIN HOMOSESEXUAL MARRIAGES}

Gender is ever present in every community member. Even visiting the bathroom requires one to adhere to their specific gender. For members of same-sex relationships, gender plays an addition role. Since heterosexuals view homosexuals as atypical, they have often tried to understand their lifestyle differences by comparing them to their own. In this fashion gendered stereotypes have appeared as a result of trying to understanding the unknown. Heterosexuals predominantly achieve this by deeming homosexual relationships as mimicking the marriages of heterosexuals. The straight world insinuates that one spouse takes on the masculine role of domination, independence and economic wealth. Meanwhile the other partner assumes the feminine role of submission, dependence and is economically reliant. In this way they are assuming the roles of husband and wife. Joseph Harry counters this claim, writing: "While pairings of masculine and effeminate men do occur in the gay world, they are far from the majority of the case," (1979: 623). He continues, discussing that it is commonly thought that the masculine role player also plays his role in 
bed being the penetrater, while the submissive partner acts as the penetrated (Ibid, 1979: 623). Bell and Weinberg confirm that these common misconceptions are flawed, insisting that same-sex couples instead focus on "task-sharing and taskflexibility" rather than submitting to the heterosexual imaginations that established such rigid stereotypical roles (Bell \& Weinberg, 1978).

Therefore it is evident that popular stereotypes are consistently inaccurate. Much of the research carried out concerning homosexual relations, dating back to the 1970s, revolves around the confirmation that gendered typecasts are false. In fact some researchers even go so far as to infer that homosexual relationships are more egalitarian than those of heterosexual relationships. This is due to the absence of cultural prescriptions which determine that one partner ought to be the dominator and the other the submissive. As a result of these cultural guidelines most, if not all, men are socialised to prioritise sex over affection and women are conditioned to emphasise the opposite (Harry, 1979: 626). It is for these reasons that books like "Men are from Mars, Women are from Venus" written by John Gray (1992) are even conceived. Socialisation plays an important role in imposing gender roles and determining acceptable ways to act. Since homosexuals do not follow any specific social norms their marital roles must be significantly "selfinvented," (Harry, 1979: 627). Their experimental way of life, which differed considerably to those in heterosexual relationships, are now established homosexual norms which most same-sex couples adhere to. The absence of strict gender-role formulas may be understood as either negative or positive. Positively it could be seen as a "state of freedom" or conversely may be viewed as a "state of anomie," (Ibid: 628). The state of freedom allows couples to develop their relationship on their own terms. While on the other hand the state of anomie suggests that incompatible expectations as to suitable role behaviours within the relationship exist, making for conflicts and hardships. According to the majority of studies however it is apparent that homosexuals have taken the lack of social rules as an opportunity to create a relationship based on the hopes and fears of the two independent beings. Therefore while the heterosexual world judges and accuses the relationships of homosexuals to mimic their own, studies show that they are commonly misunderstood. Harry \& Lovely studies confirm that a mere "one percent" within the study sample described themselves as a "houseperson," (1979: 186). These studies have shown that while gendered elements exist in society, they are subjective opinions portrayed by the majority who happen to be heterosexual.

\section{PROMISCUITY AND INFIDELITY}

Another common gender conception that stereotypes have fashioned is that single and coupled gay men are excessively promiscuous while lesbians tend to depend on one stable relationship. Unlike the typecast of marital roles between homosexual couples, this stereotype appears to possess more truth. Many lesbians and gay men do choose to be single rather than to commit to marriage like relationships. Single homosexuals are often viewed as self-reliant, be sexually experimental and thrive on excitement, in addition to having a more active involvement in the gay community (Thompson, 1983). This independence frequently provides the individual with heightened opportunities for accumulating sexual partners. Another reason homosexuals often choose to remain single is that they have not completely accepted the homosexual way of life and prefer to hide it from the heterosexual world, taking sexual encounters over relationships (Harry, 1979: 628). Saghir and Robins argue that gay liaisons are not habitually sexually exclusive (1979: 57). They confirm that "infidelity was characteristic of the majority of homosexual males," (Ibid: 57). Schafer's findings describe comparable data where a mere 16 percent of males were faithful to their partners of more than two years while only 46 percent remained faithful over a period less than two years (1977: 361-63). These infidelity rates are thought to be a result of social conditioning that men experience whilst developing. Male socialisation is focused primarily on sex and independence, thus embedding into males the need to satisfy sexual desires rather than emotional requirements. Females comparably, have been socialised as natural nurturers and care-givers, making them the perfect candidates for housewifery. Therefore females in same-sex relationships practice the most fidelity, while heterosexual relationships are a compromise of such values with the woman limiting the male's predisposition toward infidelity (Gagnon \& Simon, 1973). The acknowledgment of addictive promiscuity in numerous homosexual men is an additional cause of concern for society. The majority of interrogations of homosexual men claimed an average of 1,000 different sexual partners throughout their lives. The majority of these sexual encounters were anonymous and usually took place at locations of homosexual association. The 
global acknowledgement of these admissions makes it unsurprising that the conservative heterosexual society continues to deem gay sex as affiliated with physical (STD's) and psychological health issues (Phy-Olsen, 2006: 117-119). These stereotypes of promiscuity and infidelity based firmly on men, distinguish the genders where women prefer stable longstanding relationships over the infidelity and casual sexual relationships of their male counterparts. Thus, gender-role association is a significant component which deciphers the gendered elements of homosexual marriage.

\section{STEREOTYPES OF HOMOSEXUALS AS PARENTS}

Gendered stereotypes play a major part in the issue of homosexual parenthood. Not only has the public typecast gays and lesbians as unfit parents, family courts have additionally made the assumption that homosexuals are incapable of raising children (Editors of the Harvard Law Review, 1990. Their reasons extend from "inherent mental illness" to lesbians being "less maternal" than heterosexual females (Ibid). These conclusive stereotypes established in the 1970 s to 1980 s have gradually been replaced as a result of research carried out in the 1990s. New research found that there was no difference between lesbian and heterosexual mothers on maternity, happiness and general mental health (Falk, 1994). The courts also suggested that gender role behaviour may become an issue when raising children, because homosexual mothers were too masculine to raise their children appropriately. However Patterson's studies concluded that the paternal sex role, the warmth towards the child and the responses to child behaviour did not vary from that of heterosexual mothers (Patterson, 2000: 1064). Even with the competent research of Patterson and Falk discrimination against homosexual parenthood persists.

Additionally, homosexuals are viewed as lacking the desire to procreate. The general public see most, if not all, gay people as free of the responsibilities of raising a child. Sullivan argues that homosexual's parental instincts can be "redirected towards the broader social good", becoming teachers, nurses, doctors and social workers instead of parents (1995: 198-199). This notion of simply forgoing parenthood is not only seen as the norm by heterosexuals. In actuality homosexual men specifically deemed being gay as equivalent to being childless (Mallon, 2004). For many men their identity as a homosexual man was seen to be incompatible with their prospective identity as a father. Interestingly homosexual men incorporate the irrational stereotypes of the heterosexual world into their own self-identity. Gay men desiring fatherhood adapt to the perceptions of how the rest of the world view them, resulting in many potential fathers voicing concerns about their future child's possible experiences at school (Berkowitz \& Marsiglio, 2007: 375). However, as Mallon investigates, "empirical evidence confirms that one's sexual orientation does not determine one's ability to love and care for a child," (2004). Sadly, however, social service professionals, society and even gay men themselves pay a great deal of attention to these unconfirmed myths.

Moreover heterosexuality and parenthood are intrinsically intertwined because of the social institution of marriage that expects procreation. It is impossible to birth a child without a man and a woman therefore the very notion of man and man giving birth is unfathomable. This concept has made gay men's access to adoption excessively mediated by bureaucratic structures that dictate a couple's capabilities of becoming parents. In this way gender is the underlying complication that many homosexual couples struggle against in the battle for parenthood. That being said it is important to recognise the social changes in heterosexual marriages in present day society, accepts more widely those couples who choose not to procreate (ABS 4102.0: 2002). This social acceptance could redefine marriage not only for heterosexual couples but also more advantageously for homosexual relationships. By redefining the notion, that procreation inevitability follows marriage, the limitations of access to marriage, suffered by homosexual couples, will be substantially alleviated.

Abnormality in a heterosexual world will continue to be judged where common misconceptions persist. Positively, homosexuals' way of life is increasingly more accepted due to the loud and proud gay activists stemming from the 1960s. These groups have created a sub-culture that provides support and acceptance to same-sex couples and in some cases, marriages, making it easier for them to act on their own accord; thus they are beginning to deconstruct previous notions of same-sex marriages. Homosexual marriage, however, remains a contested issue, with very few states legalising what heterosexuals take for granted. While the gendered stereotypes of gay marriages are mostly out of date it is interesting that prejudices still occur in same-sex parenting and public opinions remain judgemental in relation to their relationship styles, even though 
numerous studies prove these typecasts false (Falk, 1994 and Patterson, 2000). What is more, as a result of social expectations of homosexual singles, many potential homosexual fathers have failed to reject the stereotypes placed on them. Instead they voice their fears of their ability to raise children. Thus, it is evident that the gendered stereotypes appropriated to homosexual parents are not only embedded in the wider community but they are also deeply engrained within the identity of homosexual fathers. Gender socialisation therefore does play a central role in homosexual marriages, from relationship roles to relationship choices and unfortunately to the rearing of children. However, through wider social acceptance of childless heterosexual couples and changing attitudes towards homosexual relationships by the heterosexual world the meaning of marriage could be redefined to incorporate homosexual couples.

\section{ACKNOWLEDGEMENTS}

The author would like to acknowledge the assistance of Rachel Bloul in the editorial process.

\section{REFERENCES}

Australian Bureau of Statistics (ABS) "Summary: Family Formation: Trends in Childlessness," 4102.0 - Australian Social Trends (2002).

Bell, A.P., and Weinberg, M.S., Homosexualities: a study of diversity among men and women, (New York, Simon and Schuster, 1978).

Editors of the Harvard Law Review. Sexual orientation and the law. (Cambridge, MA: Harvard University Press, 1990).

Falk, P., "The gap between psychosocial assumptions and empirical research in lesbian-mother child custody cases," In A.E. Gottfried (Ed.), Redefining Families: Implications for children's development (New York: Plenum, 1994) pp. 131-156.

Gagnon, J., \& Simon, W. Sexual conduct. (Chicago: Aldine, 1973).

Harry, J., \& Lovely, R. "Gay marriages and communities of sexual orientation. Alternative Lifestyles, $(1979,2)$, pp. 177- 200.

Mallon, G. Gay men choosing parenthood. (New York: Columbia University Press, 2004).

Patterson, C.J. "Family relationships of lesbians and gay men. Journal of Marriage and the Family, (62: 2000), pp. 1052-1069.

Phy-Olsen, A., Historical Guides to Controversial Issues in America: Same-Sex Marriage, (Westport, Connecticut and London, Greenwood Press, 2006).
Saghir, M., \& Robins, E. Male and female homosexuality. (Baltimore: Williams \& Wilkins, 1973).

Schafer, S. "Sociosexual behaviour in male and female homosexuals. Archives on Sexual Behaviour, $(1977,6)$, pp. 355-367.

Stewart, C. Homosexuality and the Law - A Dictionary (California: ABC - CLIO, 2001)

Sullivan, A., Virtually Normal: An Argument about Homosexuality (New York: Vintage Books, 1995), pp. 198-199.

Talbot, D. Homosexual women and men in Australian and New Zealand: A Resource Book, (Perth: Gay Counselling Service W.A., 1985).

Thompson, N., "Gay relationships: the myths demolished," The Sydney Morning Herald, (September $28^{\text {th }}, 1983$ ).

Wilkins, R.G., The Constitutionality of Legal Preferences for Heterosexual Marriage", in Lynn D. Wardel et al. Marriage and Same-Sex Unions: A Debate (Westport, CT: Praeger, 2003), p. 232.

Witte, J. Jr., "Reply to Professor Mark Strasser", in Wardel, L. D., et al. Marriage and Same-Sex Unions: A Debate (Westport, CT: Praeger, 2003), p. 43 